\title{
Identification of presynaptic neurotoxin complexes in the venoms of three Australian copperheads (Austrelaps spp.) and the efficacy of tiger snake antivenom to prevent or reverse neurotoxicity
}

\author{
Francesca Marcon and Graham M. Nicholson \\ Neurotoxin Research Group, School of Medical \& Molecular Biosciences, University of \\ Technology, Sydney, NSW, Australia
}

Correspondence: Professor Graham Nicholson, PhD, Neurotoxin Research Group, School of Medical \& Molecular Biosciences, University of Technology, Sydney, PO Box 123, Broadway, NSW, 2007, Australia

Fax: +61 29514 8206; Tel: +61295142230

URL: http://datasearch2.uts.edu. au/science/staff/medical/details.cfm?Staffld=503

E-mail: Graham.Nicholson@uts.edu.au

Running Title: Neurotoxicity of Australian copperhead snake venoms

Abbreviations: $A C h$, acetylcholine; ANOVA, analysis of variance; $B C A$, bicinchoninic acid; BSA, bovine serum albumin; CBCNM preparation, chick biventer cervicis nervemuscle preparation; CCh, carbachol; FPLC, fast-perfusion liquid chromatography; $L_{50}$, median lethal dose; MALDI-TOF, matrix-assisted laser desorption ionisation time-of-flight; SEM, standard error of the mean; SPAN, snake presynaptic SPLA ${ }_{2}$ neurotoxin; $\mathrm{SPLA}_{2}$, secretory phospholipase $A_{2}$; TSAV, monovalent tiger snake antivenom; $t_{90}$, time to $90 \%$ neuromuscular blockade; $V_{e}$, elution volume; $V_{o}$, void volume;

Keywords: snake presynaptic phospholipase $\mathrm{A}_{2}$ neurotoxin; Austrelaps; Australian copperhead; snake antivenom; neurotoxicity; neurotransmitter release 


\section{Abstract}

The venom of the Australian lowlands copperhead, Austrelaps superbus, produces significant and potentially lethal neurotoxic paralysis in cases of clinical envenomation. However, little is known about the neurotoxic components within this venom or venoms from the related alpine copperhead (Austrelaps ramsayi) or pygmy copperhead (Austrelaps labialis). Using the isolated chick biventer cervicis nerve-muscle preparation, all Austrelaps venoms were found to exhibit potent and rapid inhibition of nerve-evoked twitch contractions and block of contractures to nicotinic agonists, consistent with postsynaptic neurotoxic activity. Following separation by size-exclusion liquid chromatography under non-denaturing conditions, all Austrelaps venoms were found to also contain a high molecular mass fraction with only weak phospholipase $A_{2}\left(P L A_{2}\right)$ activity that caused a slow inhibition of twitch contractions, without inhibiting contractures to nicotinic agonists. These actions are consistent with the presence of additional snake presynaptic PLA 2 neurotoxin (SPAN) complexes in all three Austrelaps venoms. However, there was no evidence of direct muscle damage produced by any Austrelaps venom or SPAN complex. Monovalent tiger snake antivenom was effective in neutralising the neurotoxicity of both whole venom and the SPAN complex. However antivenom was unable to effectively reverse whole venom neurotoxicity, or prejunctional SPAN neurotoxicity, once established. Given the strong neurotoxicity of all Austrelaps venoms, particularly $A$. ramsayi and $A$. labialis, effective bites from these copperhead species should be considered potentially lethal. Furthermore, clinicians need to be aware of possible irreversible presynaptic neurotoxicity following envenomation from all copperhead species and that early antivenom intervention is important in preventing further development of toxicity. 


\section{Introduction}

Despite Australia being home to some of the world's most venomous snakes, there are only around 2 deaths per year, despite 1000-3000 cases of snakebite (White, 1998). This is due to Australia possessing high quality species-specific antivenoms, well-trained emergency and intensive care medical services and effective first aid techniques that specifically assist in elapid snakebite (Currie, 2006). To maintain such a low rate of mortality, despite increasing population spread, adequate knowledge of the likely clinical actions of all potentially dangerous snake venoms is critical.

An important complication of systemic envenomation by many Australian elapid snakes is skeletal muscle paralysis due to the presence of neurotoxins. If left untreated, systemic neurotoxicity can lead to paralysis of respiratory muscles, ultimately resulting in death by asphyxiation. Although these neurotoxic components have been pharmacologically characterised from the venoms of several Australian snakes, many others have been understudied. Members of the genus Austrelaps, the Australian copperheads (Worrell, 1963; Serpentes: Elapidae: Acanthophiinae), are among those that have been poorly characterised with limited biochemical or pharmacological studies. Importantly these snakes should not be confused with North American copperheads belonging to the genus Agkistrodon. It is generally accepted that there are three species within the Austrelaps genus (Rawlinson, 1991): A. superbus (common or lowland copperhead, Günther, 1858), A. ramsayi (alpine or highland copperhead, Krefft, 1864) and $A$. labialis (pygmy or Adelaide Hills copperhead, Jan, 1859). These snakes prefer cooler climates and are usually found in damp areas around streams, rivers, swamps or marshlands and are distributed in the southeastern states of Victoria and Tasmania, the highlands of New South Wales and southern parts of South Australia (Fig. 1).

Whilst there is a paucity of clinical data on copperhead envenoming, the toxicity of $A$. superbus venom has been established, with a median lethal dose $\left(\operatorname{LD}_{50}\right)$ of $0.50 \mathrm{mg} / \mathrm{kg}$ (s.c. in mice with $0.1 \% \mathrm{BSA}$ ), exactly the same lethality as that of the Indian cobra Naja naja (Broad et al., 1979). Furthermore, $A$. superbus has been attributed to at least one human fatality and profound paralysis in a dog following envenoming (Sutherland and Tibballs, 2001). Given the high venom potency and venom yield of 26-85 mg (Sutherland and Tibballs, 2001), A. superbus should be regarded as dangerous and capable of lethal envenomation. To date, a number of coagulopathic proteins, including anticoagulants and inhibitors of platelet aggregation have been characterised from this venom (Singh et al., 2000; Subburaju and Kini, 1997; Yuan et al., 1993) and one study has reported the 
presence of myotoxic fractions causing myoglobinuria (Mebs and Samejima, 1980). However, while an anticoagulation coagulopathy is observed, symptoms of major myolysis and defibrination coagulopathy are not commonly observed in a clinical setting as they are with tiger snake envenoming. Despite these studies, there is very limited knowledge about the neurotoxicity of this venom with a single study indicating the likely presence of postsynaptic neurotoxins (Hodgson et al., 2003).

While the yield of venom from $A$. ramsayi and $A$. labialis is very low, the $L_{50}$ values were found to be $0.6 \mathrm{mg} / \mathrm{kg}$ and $1.3 \mathrm{mg} / \mathrm{kg}$, respectively (Sutherland and Tibballs, 2001). However there is little data available about the venom components of these two species compared to $A$. superbus. To date, there is only one study that describes the venom composition of $A$. ramsayi using a proteomics approach to identify proteins by mass and sequence homology (Birrell et al., 2007). Similarly, there is a single published study describing the venom composition of $A$. labialis, using transcriptomics to sequence cDNA from the venom gland of a specimen and identify proteins by sequence homology (Doley et al., 2008). A limitation with proteomics- and transcriptomics-based approaches is that proteins identified by sequence homology provide little if any information about their pharmacological action(s) or their potency, nor can they identify non-covalently bound protein complexes. These previous studies have shown that secretory phospholipase $A_{2}$ (sPLA $)_{2}$ ) enzymes are present in the venoms of all three copperheads (Birrell et al., 2007; Doley et al., 2008). However, the pharmacological activities of SPLA $A_{2}$ enzymes are quite diverse: neurotoxic \pm myotoxic, cardiotoxic, convulsant or coagulopathic activity (Kini, 1997).

In addition to the common postsynaptic a-neurotoxins that block junctional nicotinic acetylcholine (ACh) receptors, monomeric SPANs (Harris et al., 1973) and multimeric SPAN complexes (Blacklow et al., 2010a; Chaisakul et al., 2010; Fohlman et al., 1976; Hodgson et al., 2007; Su et al., 1983) have been isolated from the venom of several Australo-Papuan elapid snakes. SPANs bind irreversibly to the presynaptic nerve terminal at the skeletal neuromuscular junction to inhibit the release of $\mathrm{ACh}$ without affecting the sensitivity of the motor endplate to ACh. Given that these toxins block neurotransmitter release in a potent and irreversible fashion, in addition to damaging the nerve terminal, knowledge of their presence can have implications for the management of envenomed patients. Therefore, in vitro studies are critical to determine the pharmacological actions of the components within these venoms, with particular attention paid to neurotoxic 
components that are responsible for the most serious complications in systemic copperhead envenomation.

Despite a series of monovalent antivenoms being available to treat envenomation by a range of different Australo-Papuan snakes, there are no specific antivenoms to treat several potentially lethal snakes, including copperheads. In these cases, monovalent antivenoms raised against other species are used, although recent evidence would suggest that Australian snake antivenoms are polyvalent and contain varying amounts of all five terrestrial snake monovalent antibodies (O'Leary and Isbister, 2009). Australian copperheads appear to share considerable biochemical, anatomical and ecological similarities with tiger snakes from the genus Notechis (Harris et al., 2000). Therefore it is not surprising that the accepted treatment for envenomation by copperheads is the administration of monovalent tiger snake antivenom (TSAV) (White, 2001). However, there is only one in vitro study (Hodgson et al., 2003) and one clinical report (Sutherland and Tibballs, 2001) demonstrating the efficacy of TSAV in preventing and reversing neurotoxicity associated with $A$. superbus venom. Furthermore, no studies have investigated the efficacy or effectiveness of TSAV to neutralise the toxicity of $A$. ramsayi and $A$. labialis venoms or prevent envenoming in human cases. Therefore knowledge of the in vitro efficacy of antivenom in preventing or reversing toxicity is critical to establish antivenom efficacy and provide supporting evidence to validate antivenom recommendations in clinical cases.

This study aimed to identify the presence of any post- or presynaptic neurotoxicity in the venoms of three Austrelaps spp., particularly the presence of any high molecular mass multimeric SPAN complexes. The study also aimed to determine the in vitro efficacy of monovalent TSAV in preventing or reversing the neurotoxicity of whole venoms or presynaptic neurotoxicity associated with any multimeric SPAN complexes.

\section{Materials and Methods}

\subsection{Venom source and storage}

Pooled $A$. superbus and pooled $A$. labialis venom was purchased from Venom Supplies Pty Ltd (Tanunda, SA). Copperheads were collected from their natural habitats in the Mt. Gambier and Kangaroo Island areas, respectively (Fig. 1). To minimise the effects of individual variations in venom (Chippaux et al., 1991), venom was collected from several snakes, pooled and lyophilized by the supplier. Due to limited availability of specimens, $A$. 
ramsayi venom milked from an individual snake was purchased from the Melbourne Museum (Melbourne, VIC), originally sourced from the Davies Plain region of Victoria. Venoms were collected from fang tips by the specimen biting down on a parafilm covered bottle and injecting the venom into a polyethylene container, in combination with the use of a polyethylene pipette tip to milk any residual venom from the fang. All venoms were supplied lyophilised and were stored at $-20^{\circ} \mathrm{C}$.

\subsection{Size-exclusion FPLC under non-reducing conditions}

Bioassay-guided fractionation of venom was performed using a Shimadzu LC-10 HPLC system. Lyophilised venoms were dissolved in ammonium acetate buffer $(0.1 \mathrm{M}, \mathrm{pH} 6.8)$ and insoluble material was removed by centrifugation at 10,000 rpm for 5 min (MiniSpin Plus centrifuge; Eppendorf, North Ryde, NSW, Australia). The supernatants (equivalent to ca. $3 \mathrm{mg}$ of venom) were then applied to a Superdex G-75 fast-perfusion liquid chromatography (FPLC) column $(10 \times 300$ mm, $13 \mu \mathrm{m}$; GE Healthcare, Sydney, NSW, Australia). The column was equilibrated with ammonium acetate buffer and samples were eluted isocratically at a flow rate of $0.75 \mathrm{ml} / \mathrm{min}$. Eluting peaks were monitored at an absorbance of 214 and $280 \mathrm{~nm}$ and were collected manually prior to freeze-drying for subsequent toxicity testing. An estimation of the molecular mass of major fractions was made by calibrating the size-exclusion column with a series of protein standards (6.5-66 $\mathrm{kDa}$ ) using the molecular weight marker kit for gel filtration chromatography (MWGF-70; Sigma-Aldrich, St. Louis, $\mathrm{MO})$ at a flow rate of $0.75 \mathrm{ml} / \mathrm{min}$. The void volume $\left(\mathrm{V}_{\mathrm{o}}\right)$ of the column was determined by running blue dextran (2000 kDa), and the elution volumes $\left(\mathrm{V}_{\mathrm{e}}\right)$ for each molecular weight standard was calculated. The estimated molecular mass of the venom fractions was determined by interpolation of a plot of log molecular mass (Da) versus retention ratio $\left(\mathrm{V}_{\mathrm{e}} / \mathrm{V}_{\mathrm{o}}\right)$ of the standards.

\subsection{Bicinchoninic acid protein assay}

Following lyophilisation of fractionated venom components, protein concentration was determined using the Quantipro ${ }^{\mathrm{TM}}$ bicinchoninic acid (BCA) protein assay kit (SigmaAldrich). Protein concentrations from $0.5-30 \mu \mathrm{g} / \mathrm{ml}$ were measured at $560 \mathrm{~nm}$ using a Titertek Multiscan ${ }^{\circledR}$ PLUS MKII (type 313) plate reader (Flow laboratories Australasia, North Ryde, NSW, Australia). Protein concentration was interpolated from a standard curve of various concentrations of bovine serum albumin type XI (Sigma-Aldrich). Yields were then expressed as a percentage of whole venom loaded onto the size-exclusion column (3 mg). 


\subsection{Isolated chick biventer cervicis nerve-muscle preparation}

Whole venom and individual fractions were tested in vitro for neurotoxic and myotoxic activity using the indirectly-stimulated isolated chick biventer cervicis nerve-muscle (CBCNM) preparation (Ginsborg and Warriner, 1960). Male Australorp chicks aged 1-8 days-old were euthanased with $\mathrm{CO}_{2}$ and exsanguinated in accordance with Institutional Animal Care \& Ethics Committee approval conforming to the Australian NHMRC Code of Practice for the use of animals in research. Each biventer cervicis muscle with accompanying nerve was attached to an isometric force transducer (ADInstruments, Belle Vista, NSW, Australia) and mounted in an $8 \mathrm{ml}$ jacketed organ bath under $1 \mathrm{gram}$ of resting tension. Organ baths contained Krebs-Henseleit solution of the following composition (mM): $\mathrm{NaCl}, 118.4 ; \mathrm{KCl}, 4.7 ; \mathrm{MgSO}_{4}, 1.2 ; \mathrm{KH}_{2} \mathrm{PO}_{4}, 1.2 ; \mathrm{NaHCO}_{3}, 25.0$; Dglucose, 11.1; and $\mathrm{CaCl}_{2}, 2.5$. This solution was bubbled with carbogen $\left(95 \% \mathrm{O}_{2}, 5 \% \mathrm{CO}_{2}\right)$ and was maintained at a temperature of $34^{\circ} \mathrm{C}$ using a Thermomix ${ }^{\circledR} \mathrm{M}$ water pump and heating system (Braun, Melsungen, Germany). Silver ring electrodes were placed around the motor nerve to provide indirect stimulation using supramaximal 30 volt square-wave pulses of $0.2 \mathrm{~ms}$ duration at $0.1 \mathrm{~Hz}$ via a Grass $\mathrm{S} 88$ stimulator (Grass Medical Instruments, Quincy, Massachusetts, USA). Data was recorded digitally using a Powerlab 2/25 data acquisition system and MACCHART v6.1.1 software (ADInstruments). The nervemuscle preparation was left to equilibrate for at least 30 minutes prior to experimentation. Exclusive electrical stimulation of the nerve was confirmed by complete blockade of twitches using $10 \mu \mathrm{M} d$-tubocurarine. Contracture responses to exogenous agonists before, and after, the addition of venom or individual fractions were recorded in the absence of indirect stimulation. The final bath concentrations and incubation times for the agonists were: ACh (1 mM, $30 \mathrm{~s})$; carbachol (CCh; $20 \mu \mathrm{M}, 60 \mathrm{~s})$ and $\mathrm{KCl}(40 \mathrm{mM}, 30 \mathrm{~s})$ (Harvey et al., 1994). Washout was then repeated until twitch tension returned to its original amplitude. In all experiments, venom or individual venom fraction $(10 \mu \mathrm{g} / \mathrm{ml})$ was left in contact with the preparation until twitch contractions were abolished, or for a maximum of 3 hours if complete block of twitch contractions did not eventuate. Timematched controls confirmed that muscle fatigue was not significant at 3 hours after introduction of muscles into the organ bath. Muscle tension from isometric force transducers was amplified using a ML221 bridge amplifier (ADInstruments) and recorded using a Powerlab 2/25 system (ADInstruments) connected to an iMac or PC computer. Data were digitised at $140 \mathrm{~Hz}$ and filtered using $50 \mathrm{~Hz}$ high-pass and 20-200 Hz low-pass filters. 


\subsection{Antivenom reversibility studies}

The efficacy of TSAV (CSL Biotherapies, Melbourne, Australia) to neutralize the activity of venom or venom fractions was assessed by preincubating the organ bath with $5 \mathrm{U} / \mathrm{ml}$ TSAV for $10 \mathrm{~min}$ prior to addition of toxin. To better approximate a clinical situation, reversibility studies were also performed by the addition of $5 \mathrm{U} / \mathrm{ml}$ monovalent TSAV at $90 \%$ inhibition of twitch contractions $\left(t_{90}\right)$.

\subsection{Secretory phospholipase $A_{2}$ assay}

Determination of the $\mathrm{PLA}_{2}$ activity of whole venom $(1 \mu \mathrm{g} / \mathrm{ml})$ and separated venom components $(1 \mu \mathrm{g} / \mathrm{ml})$ was determined using a colourimetric sPLA $\mathrm{A}_{2}$ assay kit (Cayman Chemical Ltd., Ann Arbor, MI, USA). This assay uses a 1,2-dithio analogue of diheptanoyl phosphatidylcholine as a substrate. Upon hydrolysis of the thio ester bond at the sn-2 position by a PLA 2 enzyme, free thiols are detected using 5,5'-dithio-bis-2-nitrobenzoic acid, producing a yellow colour. Absorbance was measured at $405 \mathrm{~nm}$ using the program KINETIC COLLECTOR V2 and a BIO-RAD model 3550-UV plate reader. Sample mix time was 2 seconds with sampling every 20 seconds for $5 \mathrm{~min}$. PLA 2 activity was expressed as micromoles of phosphatidylcholine hydrolysed per minute per milligram $(\mu \mathrm{mol} / \mathrm{min} / \mathrm{mg})$ of enzyme. Whole bee venom (Apis mellifera) $(1 \mu \mathrm{g} / \mathrm{ml})$ was used as a positive control.

\subsection{Mass spectrometry}

Matrix-assisted laser desorption ionisation time-of-flight (MALDI-TOF) mass spectrometry was performed on a Voyager DE STR mass spectrometer with a nitrogen laser (337 nm; 2 ns pulse) from PE Biosystems (Framingham, MA, USA). All analyses were performed in the positive ion linear mode with delayed extraction. Crude venom samples were dissolved in MilliQ water $(1 \mathrm{mg} / \mathrm{ml})$. Samples $(0.1-0.2 \mu \mathrm{L})$ were mixed on plate containing 0.8-1.0 $\mu \mathrm{L}$ caffeic acid matrix [10 mg/ml in trifluoroacetic acid-water-acetonitrile $(0.1: 20: 80, \mathrm{v} / \mathrm{v} / \mathrm{v})]$. Spectra were calibrated with a mixture of synthetic standards (Calmix 3, 5.7-17 kDa mass range) in the Sequazyme ${ }^{\circledR}$ peptide mass standards kit (Applied Biosystems, Melbourne, Australia) using the same matrix. Spectra were processed using DATA EXPLORER software (Applied Biosystems).

\subsection{Chemicals and drugs}

Unless otherwise specified, all chemicals used were of analytical grade and supplied by Sigma-Aldrich, Castle Hill, NSW, Australia. 


\subsection{Data analysis}

Twitch tension and contractile responses to exogenous agonists were expressed as a percentage of the corresponding value before the addition of venom or purified venom fractions. The time taken to reduce the indirectly-stimulated twitch contractions by $90 \%$ $\left(t_{90}\right)$ was calculated to provide a quantitative measure of neurotoxicity. Values for $t_{90}$ were calculated for each experiment by determining the elapsed time after toxin addition at $10 \%$ of the initial twitch contraction amplitude, and then the means and standard error of the means (SEM) were calculated. Statistical differences were determined by a one-way or two-way analysis of variance (ANOVA). All ANOVAs were followed by pairwise multiple comparisons using a Bonferroni post-hoc test, and a p-value of 0.05 was employed for all statistical analyses. Statistical and linear regression analyses were accomplished using PRISM 5.0 software package (GraphPad Software, San Diego, CA, USA). Unless otherwise stated, data are expressed as the mean \pm SEM.

\section{Results}

\subsection{Neurotoxicity of whole venom}

All Austrelaps venoms $(10 \mu \mathrm{g} / \mathrm{ml})$ produced a rapid block of indirectly-stimulated (nerveevoked) twitch contractions in the isolated CBCNM preparation as compared to timematched controls (Fig. 2Aa and closed circles in Fig. 2C-E). The times to 90\% neuromuscular blockade $\left(t_{90}\right)$ for inhibition of twitch tension by $A$. superbus, $A$. ramsayi and A. labialis were $48 \pm 5 \min (n=12), 20 \pm 1 \min (n=3)$ and $24 \pm 1 \min (n=5)$, respectively (Fig. $2 \mathrm{~F}$ ). The $t_{90}$ values of $A$. ramsayi and $A$. labialis venoms were not significantly different ( $p>0.05$, one-way ANOVA), however both venoms produced significantly more rapid neuromuscular blockade than $A$. superbus venom $(p<0.05$ in both cases, one-way ANOVA; Fig. 2F). All venoms also caused significant inhibition of contractile responses to the exogenous nicotinic agonists, ACh and CCh $(p<0.001-0.0001$, two-way ANOVA; Fig. $3 A$ and black bars in Fig. 3B-C). This is indicative of postsynaptic neurotoxicity with all three Austrelaps venoms. However, there was no significant inhibition of contractile responses to $\mathrm{KCl}$ ( $p>0.05$, two-way ANOVA; black bars in Fig. 3D), and no change in baseline muscle tension (eg. Fig. 2A), indicating a lack of overt myotoxicity with any of these venoms.

Monovalent tiger snake antivenom $(5 \mathrm{U} / \mathrm{ml})$, added to the isolated CBCNM preparation 10 min prior to the addition of venom, was able to effectively neutralise the neurotoxic 
components of all three venoms. Antivenom prevented any significant inhibition of twitch contractions ( $p>0.05$ vs. time-matched control, one-way ANOVA; Fig 2B and grey circles in Fig. 2C-E) or nicotinic agonist responses ( $p>0.05$, two-way ANOVA; grey bars in Fig. $3 \mathrm{~B}-\mathrm{C})$ by all three venoms.

Due to the presence of rapidly-acting postsynaptic neurotoxicity, the presence of any slower-acting presynaptic neurotoxins within these venoms is likely to be masked. To ascertain if Austrelaps venoms contain irreversible presynaptic neurotoxic component(s), 5 $\mathrm{U} / \mathrm{ml}$ TSAV was added to the isolated CBCNM preparation at $90 \%$ neuromuscular blockade $\left(t_{90}\right)$. The potential presence of presynaptic neurotoxins would be indicated by a lack of reversal of twitch tension but the return of exogenous nicotinic agonist responses. After a 3 hour TSAV application period, there was no restoration of twitch contractions with either $A$. superbus or $A$. labialis venoms and neuromuscular transmission remained completely inhibited $(p<0.0001$ vs. time-matched control for both venoms, one-way ANOVA; open circles in Figs. 2B and 2D). In contrast, there was a partial recovery of twitch contractions when TSAV was added at $t_{90}$ following application of $A$. ramsayi venom (Fig. 2Ab) but this was still inhibited compared to time-matched controls (35 $\pm 1 \%, n=2$ due to limited material, open circles in Fig. 2C). Importantly, however, contractile responses to ACh were restored to control levels following application of TSAV at $t_{90}$ with all three venoms ( $p>0.05$ vs. control, two-way ANOVA; open bars in Fig. 3B). Overall, these results are consistent with the likely presence of an irreversible presynaptic component within each Austrelaps venom. The partial recovery of A. ramsayi venominduced neuromuscular blockade following TSAV may also indicate the presence of less potent or lower abundance presynaptic neurotoxins. Interestingly, contractile responses to CCh were not significantly reversed following application of $5 \mathrm{U} / \mathrm{ml}$ TSAV at the $t_{90}$ value for all three venoms (open bars in Fig. 3C). This reversal of ACh responses, but not CCh responses, following application of antivenom has been previously noted for pseudoirreversible postsynaptic $\alpha$-neurotoxins such as papuantoxin-1 (Kuruppu et al., 2005b).

\subsection{Venom fractionation}

Fractionation of Austrelaps spp. venoms using size-exclusion FPLC, under non-reducing conditions, produced 4-6 major peaks with a similar chromatographic pattern (Fig. 4B-D). Following calibration of the size-exclusion column using a set of molecular mass markers (Fig. 4A), the retention times of early-eluting fractions were found to be consistent with a molecular mass range between $41 \mathrm{kDa}$ to $>66 \mathrm{kDa}$ (early shaded fraction labelled ' $f 1$ ' in Fig. 4B-D). Given that the calibration of the size-exclusion Sephadex G-75 column may not 
be linear beyond $66 \mathrm{kDa}$ (bovine serum albumin was the highest mass calibrant tested) or below $6.5 \mathrm{kDa}$ (aprotinin was the lowest mass calibrant tested), we have elected not to extrapolate beyond these upper and lower limits. Considering that the smallest known multimeric SPAN complex is dimeric $\beta$-bungarotoxin (21 kDa) (Chu et al., 1995) and the largest is hexameric textilotoxin (ca. $87 \mathrm{kDa}$ ) (Aquilina, 2009), the criteria used to determine the presence of a SPAN complex in the present study was therefore that the molecular mass range of the first eluting fraction had to fall between these two masses. The retention ratio $\left(\mathrm{V}_{\mathrm{e}} / \mathrm{V}_{\mathrm{o}}\right)$ and molecular mass range of the early eluting fraction $(f 1)$ were consistent with the presence of a large molecular mass component within this fraction in all three Austrelaps venoms (Table 1). The percent yield of each high molecular mass $f 1$ fraction, as determined by the BCA protein assay, varied between $4.9-14.4 \%$ (Table 1). In the lower mass regions of the venom profile, each venom presented distinct differences in the abundance of proteins with retention times consistent with monomeric sPLA 2 proteins (17-17.4 min, 12,700-14,800 kDa) or postsynaptic a-neurotoxins (18.4$19.2 \mathrm{~min}, 6,700-8,850 \mathrm{kDa}$ ). Austrelaps superbus venom was significantly richer in monomeric sPLA 2 proteins, $A$. ramsayi was almost completely dominated by postsynaptic a-neurotoxins, while $A$. labialis appears to express both types of proteins to a similar degree.

\subsection{Neurotoxicity studies of the high molecular mass fraction}

To determine the presence of any multimeric SPAN complex, each high molecular mass $f 1$ fraction $(10 \mu \mathrm{g} / \mathrm{ml})$ was bioassayed using the isolated CBCNM preparation. The $f 1$ fraction from all three venoms produced a slow time-dependent inhibition of indirect twitch contractions (closed squares in Fig. 5A-C) whereas with time-matched controls there was no significant inhibition of twitch tension over a 270 min period (open triangles in Fig. 5AC). The $t_{90}$ values for inhibition of twitch tension by $A$. superbus, $A$. ramsayi and $A$. labialis were $130 \pm 2 \min (n=6), 69 \pm 3 \min (n=3)$ and $68 \pm 6 \min (n=3)$, respectively (Fig. 5D). The $t_{90}$ values for fraction $f 1$ from $A$. ramsayi and $A$. labialis venoms were not significantly different ( $p>0.05$, one-way ANOVA), however both $f 1$ fractions produced significantly more rapid neuromuscular blockade than fraction $f 1$ from $A$. superbus venom $(p<0.0001$ in both cases, one-way ANOVA; Fig. 5E). Despite a potent, albeit slow, action to completely inhibit twitch contractions, fraction $f 1$ from all Austrelaps venoms failed to significantly inhibit contractile responses to $\mathrm{ACh}, \mathrm{CCh}$ or $\mathrm{KCl}$, and there was no change in baseline muscle tension ( $p>0.05$, two-way ANOVA; Fig. 6A-C). This is indicative of presynaptic neurotoxicity without overt direct muscle damage within fraction $f 1$ from all 
three Austrelaps venoms. These actions are consistent with the presence of an irreversible multimeric SPAN complex.

Addition of $5 \mathrm{U} / \mathrm{ml}$ TSAV to the isolated CBCNM preparation $10 \mathrm{~min}$ prior to the addition of fraction $f 1$, was able to effectively neutralise the neurotoxic activity of fraction $f 1$ from $A$. superbus and $A$. labialis venoms (fraction $f 1$ from $A$. ramsayi was not tested due to limited material) ( $p>0.05$ vs. time-matched control, one-way ANOVA; grey squares in Figs. 5B and 5D). Contractile responses to $\mathrm{ACh}, \mathrm{CCh}$ and $\mathrm{KCl}$ remained uninhibited ( $p>0.05$ vs. control, two-way ANOVA; open bars in Figs. 6A-C).

Addition of $5 \mathrm{U} / \mathrm{ml}$ TSAV at $90 \%$ neuromuscular blockade (i.e. at $t_{90}$ ), induced by each fraction $f 1$, failed to restore neuromuscular transmission. After a 130-230 min TSAV application period, there was no restoration of twitch contractions with fraction $f 1$ from any Austrelaps venom and neuromuscular transmission remained completely inhibited $(p<$ 0.0001 vs. time-matched control for all venoms, one-way ANOVA; open squares in Figs. $5 A-C)$.

Contractile responses to $\mathrm{ACh}, \mathrm{CCh}$ and $\mathrm{KCl}$ also remained uninhibited in the presence of $f 1$ ( $p>0.05$ vs. time-matched control, two-way ANOVA; closed bars in Fig. 6A-C). Interestingly, the responses to $\mathrm{CCh}$ and, to a lesser extent, $\mathrm{ACh}$ were significantly enhanced in toxin-free time-matched controls recorded at 3-5 hours in comparison to responses recorded at time zero (striped bars vs. dashed line in Fig. 6A-C). This may reflect time-dependent sensitization of the tissue to cholinergic agonists in the absence of nicotinic receptor antagonists, and has been previously reported in the CBCNM preparation (Blacklow et al., 2010a; Kuruppu et al., 2005a; Lumsden et al., 2005).

\subsection{PLA 2 activity}

The PLA $A_{2}$ activity of the positive control, bee venom, was $262 \pm 14 \mu \mathrm{mol} / \mathrm{min} / \mathrm{mg}(\mathrm{n}=11)$, comparable to previous studies. However, the $\mathrm{PLA}_{2}$ activity of whole Austrelaps venoms and $f 1$ fractions were significantly lower than the positive control. In addition, the $\mathrm{PLA}_{2}$ activity of whole venoms and $f 1$ neurotoxic fractions from Austrelaps spp. showed considerable within-genus variability (Fig. 7). $\mathrm{PLA}_{2}$ activity of the least neurotoxic venom from $A$. superbus possessed the highest enzymatic activity of $152 \pm 5$ (whole venom, $n=$ 3 ) and $7 \pm 2(f 1$ fraction, $n=4) \mu \mathrm{mol} / \mathrm{min} / \mathrm{mg}$. In contrast, the $\mathrm{PLA}_{2}$ activity of both whole venom and $f 1$ fraction from $A$. ramsayi, which both caused marked neurotoxicity, could not be detected in the same assay. In support, phospholipase $A_{2}$ activity of less than 1 
$\mu \mathrm{mol} / \mathrm{min} / \mathrm{mg}$ has been previously reported for some Australian elapid venoms including several Pseudechis spp., as well as Notechis scutatus (Ramasamy et al., 2004).

\subsection{Mass spectrometry}

All venoms shared a similar pattern of components in their size-exclusion FPLC chromatograms. However, there were differences in the retention time and relative absorbance of these components between Austrelaps venoms. To determine any similarity between these venoms, in terms of the types of toxins they contain and their relative abundance, a mass profile of each venom was obtained using MALDI-TOF mass spectrometry. The mass spectra were dominated by high-intensity ions in the $\mathrm{m} / \mathrm{z}$ regions of 6300-6700, 6700-6900, 7300-8300 and 12700-14800 m/z ranges (Fig. 8). These mass ranges are consistent with Kunitz-type protease inhibitors, short-chain a-neurotoxins, long-chain $\alpha$-neurotoxins and $\mathrm{sPLA}_{2}$ proteins, respectively. Unfortunately, this data does not indicate if any $\mathrm{SPLA}_{2}$ proteins are monomeric SPANs, coagulopathic or myotoxic $\mathrm{sPLA}_{2}$ proteins, or represent dissociated $\mathrm{sPLA}_{2}$ components of a multimeric SPAN complex. Allowing for minor differences in measurement from external calibration, all venoms share comparable short-chain a-neurotoxins at $m / z 6767$, also previously reported using LC-ESI mass spectrometry (Hodgson et al., 2003), and $A$. superbus and $A$. labialis share comparable short-chain a-neurotoxins at $m / z 6817$ (see highlighted masses in Fig. 8), although the molecular identity of these proteins would need to be confirmed via Edman sequencing. $A$. superbus and $A$. labialis also share comparable long-chain $\alpha-$ neurotoxins at $m / z 7336$ and 7352 and sPLA 2 proteins at $m / z 13529$, while $A$. ramsayi and A. labialis share comparable long-chain a-neurotoxins at $m / z$ 8071. Interestingly, $A$. ramsayi has a low abundance of $\mathrm{SPLA}_{2}$ proteins and does not share any equivalent sPLA 2 proteins with $A$. superbus or $A$. labialis. $A$. ramsayi venom is also dominated mainly by the presence of long-chain $\alpha$-neurotoxins. This finding is also supported by the size-exclusion FPLC chromatogram profile (Fig. 4C). These differences may result from different prey species and resultant selection pressures on venom composition given that the $A$. ramsayi is restricted to higher altitudes and more northerly areas. Indeed, it is the only Australian venomous snake that lives above the snowline.

Perhaps the majority of sPLA 2 proteins detected in the MALDI-TOF mass spectra for $A$. ramsayi venom are only associated with the multimeric SPAN complex and do not exist as monomers. This would explain why the relative absorbance of the 'PLA ${ }_{2}$ fractions in the 
size-exclusion chromatogram for $A$. ramsayi was so much lower than that of $A$. superbus and $A$. labialis.

\section{Discussion}

The venoms of all three species of Australian copperhead were found to contain clear evidence of postsynaptic neurotoxicity, as demonstrated by the rapid inhibition of nervemediated twitch contractions and the inhibition of contractile responses to exogenous nicotinic receptor agonists. Furthermore, these results are supported by the presence of a range of short- and/or long-chain postsynaptic a-neurotoxins in the MALDI-TOF analysis of all Austrelaps venoms.

Vertebrate $L_{50}$ studies, as a means to rank snake venom lethality, have been largely superseded by in vitro studies as a result of the complex regulatory requirements and ethical considerations in Australia and many other countries. To overcome this issue, a common method of assessing snake venom neurotoxicity is to determine $t_{90}$ values in isolated nerve-muscle preparations (Harvey et al., 1994). Austrelaps venoms display intermediary neurotoxic potency compared with other Australian elapid snakes, showing higher potency than taipan (Oxyuranus) and most black and mulga snake (Pseudechis) venoms, but less potency than death adder (Acanthophis) venoms (Table 2) and IndoPacific sea snake venoms (Chetty et al., 2004). Of the three venoms, $A$. superbus venom displayed the least neurotoxicity ( $t_{90}=48 \pm 5 \mathrm{~min}$ ) despite having the lowest $L D_{50}$ value (Broad et al., 1979). However, it has been observed that the rank order of venom lethality, as determined from $L_{50}$ values, often differs to the rank order of $t_{90}$ values (Kuruppu et al., 2008). The $\mathrm{LD}_{50}$ no doubt reflects contributions of other coagulopathic toxins, myotoxins, or neurotoxins with slow on-rates (ie SPANs) to overall toxicity, whereas the $t_{90}$ is influenced by neurotoxins with more rapid association kinetics such as postsynaptic $\alpha$ neurotoxins. One explanation as to why $A$. superbus venom has a $t_{90}$ value that is significantly prolonged compared to $A$. ramsayi and $A$. labialis venoms appears to be because $A$. superbus venom contains far fewer rapidly-acting short- and long-chain $\alpha-$ neurotoxins in comparison to the other two Austrelaps venoms (Figs. 4 and 7).

Previously, venom fractions from $A$. superbus venom have been shown to cause myoglobinuria in mice suggestive of a myolytic action (Mebs and Samejima, 1980). Furthermore $A$. superbus venom has been shown to produce inhibition of twitches evoked by direct muscle stimulation and a slowly developing contractile response (Hodgson et al., 
2003) although, like the present study, responses to $\mathrm{KCl}$ were unaffected. In contrast, the present study failed to show any clear evidence of myotoxicity, especially a lack of a slowly developing increase in baseline muscle tension, from either whole venom or high molecular mass fractions from all three Austrelaps venoms. This agrees with clinical reports that, unlike Notechis envenoming, major myolysis is not a common symptom in copperhead envenoming (White, 1998). However, myolysis should not be discounted as myotoxic effects may not be observed as rapidly as postsynaptic neurotoxic effects (Wickramaratna et al., 2003).

Monovalent tiger snake antivenom has previously been shown to be effective in neutralising the neurotoxicity of $A$. superbus venom in vitro (Hodgson et al., 2003). Hodgson et al. (2003) also demonstrated a partial ca. 25\% recovery of nerve-evoked twitch contractions 3 hours after addition of TSAV. The present study confirms the effectiveness of TSAV in preventing the neurotoxicity of $A$. superbus venom, however, addition of TSAV at $90 \%$ neuromuscular blockade failed to reverse the inhibition of twitch contractions. Nevertheless, the present study demonstrates for the first time that TSAV is effective in preventing the neurotoxicity caused by $A$. ramsayi and $A$. labialis venoms. Whilst the addition of TSAV at $90 \%$ neuromuscular blockade failed to reverse the inhibition of twitch contractions in $A$. labialis venom, there was a slight recovery of twitch contractions with $A$. ramsayi venom over the course of 3 hours. The MALDI-TOF mass profiles and size-exclusion chromatograms reveal that sPLA $\mathrm{A}_{2}$ enzymes are more abundant in $A$. superbus and $A$. labialis venoms than $A$. ramsayi venom, which is dominated by postsynaptic a-neurotoxins. Neurotoxicity associated with several postsynaptic $\alpha$ neurotoxins is generally accepted to be 'reversible' or 'pseudo-irreversible' whereas the neurotoxicity associated with many $\mathrm{SPLA}_{2}$ neurotoxins, particularly SPAN complexes, is irreversible. This may be due to $\mathrm{PLA}_{2}$-mediated damage to the nerve terminal that facilitates SPAN entry (Rigoni et al., 2008), resulting in a loss of accessibility of antibodies for the SPAN complex following internalisation of the toxin into the nerve terminal. Interestingly, the size-exclusion chromatogram of $A$. ramsayi venom shows that the second major fraction has a delayed retention time $(17.4-21.3 \mathrm{~min})$ in comparison to $A$. superbus and $A$. labialis venoms (14.5-21.6 and 14.7-21.6 $\mathrm{min}$, respectively). The estimated mass range of this fraction, from interpolation using the standard curve, suggests the presence of only $\alpha$-neurotoxins with masses between $<6.5-12.8 \mathrm{kDa}$ with a peak at $7.7 \mathrm{kDa}$. This indicates why the neurotoxicity caused by $A$. ramsayi venom is more readily reversible with TSAV than with $A$. superbus and $A$. labialis venoms. 
The high molecular mass fraction in all three venoms caused a time-dependent inhibition of nerve-evoked twitch contractions without inhibiting contractile responses to exogenous nicotinic receptor agonists. Given that the activity of this fraction is prejunctional and falls within a molecular mass range that is consistent with that of multimeric SPAN complexes previously isolated (Table 1), we therefore propose that these fractions contain multimeric SPAN complexes. In support, we previously surmised that a number of Acanthophis venoms contain multimeric SPAN complexes based on a similar approach to that used in the present study (Blacklow et al., 2010b). This approach has subsequently been validated following the characterisation of the heterotrimeric SPAN complexes from these Acanthophis venoms (Blacklow et al., 2010a; Chaisakul et al., 2010). At this point it is difficult to determine the subunit composition of the SPAN complexes given the broad mass range of fraction $f 1$ ( 42 to $>66 \mathrm{kDa}$ ). Elapid venoms are known to contain high molecular mass proteins, in addition to multimeric SPAN complexes, including C-type lectins (Lin et al., 2007), acetylcholinesterases (Frobert et al., 1997) and L-amino acid oxidases (Jin et al., 2007). The latter two enzymes have previously been identified in $A$. superbus venom (Tan and Ponnudurai, 1990). Despite this the estimated mass of the SPAN complex would be consistent with at least three $\mathrm{sPLA}_{2}$ subunits. The composition of the SPAN complex from each Austrelaps venom is likely to be homologous, but not identical given that the MALDI-TOF mass profiles indicate little conservation of $\mathrm{SPLA}_{2}$ proteins between $A$. superbus, A. ramsayi and A. labialis venoms (Fig. 7). This may explain slight differences in potencies of the high molecular mass fractions.

A reason why PLA $\mathrm{P}_{2}$ activity may have been low, or not detected, in the high molecular mass fractions could be due to the presence of acetylcholinesterases and L-amino acid oxidases in this fraction that may dilute the apparent concentration of the multimeric SPAN complexes. Regardless, previous studies indicate there is little correlation between PLA 2 activity and the degree of neurotoxicity. For example, SPANs such as notexin, from Notechis scutatus, have substantial neurotoxic activity and low PLA 2 activity, whilst others, such as Naja nigricollis neutral $\mathrm{SPLA} \mathrm{A}_{2}$ enzyme, are weakly neurotoxic but have significant $\mathrm{PLA}_{2}$ activity (Rosenberg, 1997; Rossetto et al., 2004).

Although monovalent TSAV was unable to reverse the prejunctional neurotoxic effects of the high molecular mass fractions in all three venoms once toxicity was well established, TSAV was found to be effective in neutralising this toxicity in $A$. superbus and $A$. labialis venoms. Unfortunately, due to limited material, this experiment was unable to be performed with the high molecular mass fraction from $A$. ramsayi. 
In conclusion, the present study has identified the presence of potent and irreversible multimeric SPAN complexes in the venoms of all three species of Australian copperheads that represents a significant component (\% w/w) of the whole venom. Therefore, clinicians need to be aware of the presence of such toxins, as early antivenom treatment is critical upon envenomation. The current study also provides the first data to validate the current clinical recommendations for the use of TSAV in the treatment of envenomation by all species of Australian copperhead. Future studies aim at characterising these presynaptic neurotoxins.

\section{Acknowledgements}

Mass spectrometric results were obtained at the Bioanalytical Mass Spectrometry Facility at the University of New South Wales using infrastructure provided by the NSW Government co-investment in the National Collaborative Research Infrastructure Scheme. Subsidised access to this facility is gratefully acknowledged.

\section{References}

Aquilina, J.A., 2009. The major toxin from the Australian Common Brown Snake is a hexamer with unusual gas-phase dissociation properties. Proteins 75, 478-485.

Birrell, G.W., Earl, S.T., Wallis, T.P., Masci, P.P., de Jersey, J., Gorman, J.J., Lavin, M.F., 2007. The diversity of bioactive proteins in Australian snake venoms. Mol Cell Proteomics 6, 973-986.

Blacklow, B., Escoubas, P., Nicholson, G.M., 2010a. Characterisation of the heterotrimeric presynaptic phospholipase $A_{2}$ neurotoxin complex from the venom of the common death adder (Acanthophis antarcticus). Biochem Pharmacol 80, 277-287.

Blacklow, B., Konstantakopoulos, N., Hodgson, W.C., Nicholson, G.M., 2010b. Presence of presynaptic neurotoxin complexes in the venoms of Australo-Papuan death adders (Acanthophis spp.). Toxicon 55, 1171-1180.

Broad, A.J., Sutherland, S.K., Coulter, A.R., 1979. The lethality in mice of dangerous Australian and other snake venom. Toxicon 17, 661-664.

Chaisakul, J., Konstantakopoulos, N., Smith, A.I., Hodgson, W.C., 2010. Isolation and characterisation of P-EPTX-Ap1a and P-EPTX-Ar1a: pre-synaptic neurotoxins from the venom of the northern (Acanthophis praelongus) and Irian Jayan (Acanthophis rugosus) death adders. Biochem Pharmacol 80, 895-902. 
Chetty, N., Du, A., Hodgson, W.C., Winkel, K.D., Fry, B.G., 2004. The in vitro neuromuscular activity of Indo-Pacific sea-snake venoms: efficacy of two commercially available antivenoms. Toxicon 44, 193-200.

Chippaux, J.P., Williams, V., White, J., 1991. Snake venom variability: methods of study, results and interpretation. Toxicon 29, 1279-1303.

Chu, C.C., Li, S.H., Chen, Y.H., 1995. Resolution of isotoxins in the $\beta$-bungarotoxin family. J Chromatogr A 694, 492-497.

Currie, B.J., 2006. Treatment of snakebite in Australia: the current evidence base and questions requiring collaborative multicentre prospective studies. Toxicon 48, 941-956.

Doley, R., Tram, N.N., Reza, M.A., Kini, R.M., 2008. Unusual accelerated rate of deletions and insertions in toxin genes in the venom glands of the pygmy copperhead (Austrelaps labialis) from Kangaroo island. BMC Evol Biol 8, 70.

Fohlman, J., Eaker, D., Karlsson, E., Thesleff, S., 1976. Taipoxin, an extremely potent presynaptic neurotoxin from the venom of the Australian snake taipan (Oxyuranus s. scutellatus). Isolation, characterization, quaternary structure and pharmacological properties. Eur. J. Biochem. 68, 457-469.

Frobert, Y., Creminon, C., Cousin, X., Remy, M.H., Chatel, J.M., Bon, S., Bon, C., Grassi, J., 1997. Acetylcholinesterases from Elapidae snake venoms: biochemical, immunological and enzymatic characterization. Biochim Biophys Acta 1339, 253-267.

Ginsborg, B.L., Warriner, J., 1960. The isolated chick biventer cervicis nerve-muscle preparation. Brit. J. Pharmacol. Chemother. 15, 410-411.

Harris, J.B., Grubb, B.D., Maltin, C.A., Dixon, R., 2000. The neurotoxicity of the venom phospholipases $A_{2}$, notexin and taipoxin. Exp Neurol 161, 517-526.

Harris, J.B., Karlsson, E., Thesleff, S., 1973. Effects of an isolated toxin from Australian Tiger snake (Notechis scutatus scutatus) venom at the mammalian neuromuscular junction. Brit. J. Pharmacol. 47, 141-146.

Harvey, A.L., Barfaraz, A., Thomson, E., Faiz, A., Preston, S., Harris, J.B., 1994. Screening of snake venoms for neurotoxic and myotoxic effects using simple in vitro preparations from rodents and chicks. Toxicon 32, 257-265.

Hodgson, W.C., Dal Belo, C.A., Rowan, E.G., 2007. The neuromuscular activity of paradoxin: a presynaptic neurotoxin from the venom of the inland taipan (Oxyuranus microlepidotus). Neuropharmacology 52, 1229-1236.

Hodgson, W.C., Eriksson, C.O., Alewood, P., Fry, B.G., 2003. Comparison of the in vitro neuromuscular activity of venom from three Australian snakes (Hoplocephalus 
stephensi, Austrelaps superbus and Notechis scutatus): efficacy of tiger snake antivenom. Clin Exp Pharmacol Physiol 30, 127-132.

Jin, Y., Lee, W.H., Zeng, L., Zhang, Y., 2007. Molecular characterization of L-amino acid oxidase from king cobra venom. Toxicon 50, 479-489.

Kini, R.M., 1997. Phospholipase $A_{2}-a$ complex multifunctional protein puzzle. In: Kini, R.M. (Ed.) Venom Phospholipase $A_{2}$ Enzymes: Structure, Function and Mechanism. John Wiley \& Sons Ltd., Chichester, pp. 1-28.

Kuruppu, S., Reeve, S., Banerjee, Y., Kini, R.M., Smith, A.I., Hodgson, W.C., $2005 a$. Isolation and pharmacological characterization of cannitoxin, a presynaptic neurotoxin from the venom of the Papuan Taipan (Oxyuranus scutellatus canni). J. Pharmacol. Exp. Ther. 315, 1196-1202.

Kuruppu, S., Reeve, S., Smith, A.I., Hodgson, W.C., 2005b. Isolation and pharmacological characterisation of papuantoxin-1, a postsynaptic neurotoxin from the venom of the Papuan black snake (Pseudechis papuanus). Biochem. Pharmacol 70, 794-800.

Kuruppu, S., Smith, A.I., Isbister, G.K., Hodgson, W.C., 2008. Neurotoxins from AustraloPapuan elapids: a biochemical and pharmacological perspective. Crit Rev Toxicol 38, 73-86.

Lin, L.P., Lin, Q., Wang, Y.Q., 2007. Cloning, expression and characterization of two Ctype lectins from the venom gland of Bungarus multicinctus. Toxicon 50, 411-419.

Lumsden, N.G., Fry, B.G., Ventura, S., Kini, R.M., Hodgson, W.C., 2005. Pharmacological characterisation of a neurotoxin from the venom of Boiga dendrophila (mangrove catsnake). Toxicon 45, 329-334.

Mebs, D., Samejima, Y., 1980. Purification, from Australian elapid venoms, and properties of phospholipases A which cause myoglobinuria in mice. Toxicon 18, 443-454.

O'Leary, M.A., Isbister, G.K., 2009. Commercial monovalent antivenoms in Australia are polyvalent. Toxicon 54, 192-195.

Ramasamy, S., Isbister, G.K., Hodgson, W.C., 2004. The efficacy of two antivenoms against the in vitro myotoxic effects of black snake (Pseudechis) venoms in the chick biventer cervicis nerve-muscle preparation. Toxicon 44, 837-845.

Rawlinson, P.A., 1991. Taxonomy and distribution of the Australian tiger snakes (Notechis) and copperheads (Austrelaps) (Serpentes, Elapidae). Proc. Royal Soc. Victoria 103, 125-135.

Rigoni, M., Paoli, M., Milanesi, E., Caccin, P., Rasola, A., Bernardi, P., Montecucco, C., 2008. Snake phospholipase A2 neurotoxins enter neurons, bind specifically to 
mitochondria, and open their transition pores. The Journal of biological chemistry 283 , 34013-34020.

Rosenberg, P., 1997. Lethal potency of snake venom phospholipase $A_{2}$ enzymes. In: Kini, R.M. (Ed.) Venom Phospholipase $A_{2}$ Enzymes: Structure, Function and Mechanism. John Wiley \& Sons Ltd., Chichester, pp. 129-154.

Rossetto, O., Rigoni, M., Montecucco, C., 2004. Different mechanism of blockade of neuroexocytosis by presynaptic neurotoxins. Toxicology Letters 149, 91-101.

Singh, S., Armugam, A., Kini, R.M., Jeyaseelan, K., 2000. Phospholipase $A_{2}$ with platelet aggregation inhibitor activity from Austrelaps superbus venom: protein purification and cDNA cloning. Arch. Biochem. Biophys. 375, 289-303.

Su, M.J., Coulter, A.R., Sutherland, S.K., Chang, C.C., 1983. The presynaptic neuromuscular blocking effect and phospholipase A2 activity of textilotoxin, a potent toxin isolated from the venom of the Australian brown snake, Pseudonaja textilis. Toxicon 21, 143-151.

Subburaju, S., Kini, R.M., 1997. Isolation and purification of superbins I and II from Austrelaps superbus (copperhead) snake venom and their anticoagulant and antiplatelet effects. Toxicon 35, 1239-1250.

Sutherland, S.K., Tibballs, J., 2001. Genus Austrelaps, death adders. Australian Animal Toxins: The Creatures, Their Toxins and Care of the Poisoned Patient. Oxford University Press, Melbourne, pp. 130-138.

Tan, N., Ponnudurai, G., 1990. A comparative study of the biological properties of australian elapid venoms. Comp. Biochem. Physiol. 97C, 99-106.

White, J., 1998. Envenoming and antivenom use in Australia. Toxicon 36, 1483-1492.

White, J., 2001. CSL Antivenom Handbook. CSL Ltd., Melbourne.

Wickramaratna, J.C., Fry, B.G., Aguilar, M.I., Kini, R.M., Hodgson, W.C., 2003. Isolation and pharmacological characterization of a phospholipase $A_{2}$ myotoxin from the venom of the Irian Jayan death adder (Acanthophis rugosus). Brit J Pharmacol 138, 333-342.

Yuan, Y., Jackson, S.P., Mitchell, C.A., Salem, H.H., 1993. Purification and characterisation of a snake venom phospholipase $\mathrm{A}_{2}$ : a potent inhibitor of platelet aggregation. Thrombosis Res. 70, 471-481. 
Table 1. Characteristics of high molecular mass neurotoxic fractions from Austrelaps venoms

$\begin{array}{cccc}\text { Venom Fraction } & \begin{array}{c}\text { Elution time } \\ (\mathrm{min})\end{array} & \begin{array}{c}\text { Approx. molecular } \\ \text { mass range }(k D a)\end{array} & \begin{array}{c}\text { Yield of fraction } \\ (\% w / w)\end{array}\end{array}$
A. superbus
$f 1 \quad 10.1-13.4$
53 to $>66$
4.9
A. ramsayi
$f 1$
$12.0-14.1$
41 to $>66$
14.4

A. labialis

$f 1$

$10.2-13.6$

49 to $>66$

7.2 
Table 2. Rank order of neurotoxicity of Australo-Papuan terrestrial elapid snake venoms in the CBCNM preparation (as determined by $t_{90}$ values)

\begin{tabular}{|c|c|c|c|}
\hline Common Name & Scientific name & $\begin{array}{c}t_{90} \text { at } 10 \mu \mathrm{g} / \mathrm{ml} \\
(\mathrm{min})\end{array}$ & Reference(s) \\
\hline Common death adder (NSW) & Acanthophis antarcticus & $10 \pm 1,14 \pm 1$ & $\begin{array}{l}\text { (Fry et al., 2001; } \\
\text { Wickramaratna } \\
\text { and Hodgson, } \\
\text { 2001) }\end{array}$ \\
\hline Curl snake & Suta suta & $13 \pm 1$ & $\begin{array}{l}\text { (Kuruppu et al., } \\
2007 \text { ) }\end{array}$ \\
\hline Black head death adder & Acanthophis wellsi & $13 \pm 2$ & $\begin{array}{l}\text { (Fry et al., 2001) } \\
\text { (Wickramaratna }\end{array}$ \\
\hline Desert death adder & Acanthophis pyrrhus & $14 \pm 1$ & $\begin{array}{l}\text { and Hodgson, } \\
\text { 2001) } \\
\text { (Wickramaratna }\end{array}$ \\
\hline Northern death adder & Acanthophis praelongus & $19 \pm 2$ & $\begin{array}{l}\text { and Hodgson, } \\
\text { 2001) }\end{array}$ \\
\hline *Highlands copperhead & Austrelaps ramsayi & $20 \pm 1$ & This study \\
\hline Yellow-banded snake & Hoplocephalus stephensi & $20 \pm 2$ & $\begin{array}{l}\text { (Hodgson et al., } \\
\text { 2003) }\end{array}$ \\
\hline Tiger snake & Notechis scutatus & $22 \pm 2$ & $\begin{array}{l}\text { (Hodgson et al., } \\
\text { 2003) }\end{array}$ \\
\hline Yellow-bellied black snake & Pseudechis butleri & $22 \pm 3$ & $\begin{array}{l}\text { (Ramasamy et } \\
\text { al., 2005) }\end{array}$ \\
\hline *Pygmy copperhead & Austrelaps labialis & $24 \pm 1$ & This study \\
\hline Spotted curl snake & Suta punctata & $25 \pm 2$ & $\begin{array}{l}\text { (Kuruppu et al., } \\
\text { 2007) }\end{array}$ \\
\hline Red-bellied black snake & Pseudechis porphyriacus & $25 \pm 2$ & $\begin{array}{l}\text { (Ramasamy et } \\
\text { al., 2005) }\end{array}$ \\
\hline *Lowlands copperhead & Austrelaps superbus & $26 \pm 3, * 48 \pm 5$ & $\begin{array}{l}\text { (Hodgson et al., } \\
\text { 2003), This } \\
\text { study }\end{array}$ \\
\hline Inland taipan & Oxyuranus microlepidotus & $27 \pm 3$ & $\begin{array}{l}\text { (Crachi et al., } \\
\text { 1999a) }\end{array}$ \\
\hline Pygmy mulga snake & Pseudechis pailsii & $28 \pm 1$ & $\begin{array}{l}\text { (Ramasamy et } \\
\text { al., 2005) }\end{array}$ \\
\hline Blue-bellied black snake & Pseudechis guttatus & $30 \pm 1$ & $\begin{array}{l}\text { (Ramasamy et } \\
\text { al., 2005) }\end{array}$ \\
\hline Papuan black snake & Pseudechis papuanus & $40 \pm 5$ & $\begin{array}{l}\text { (Ramasamy et } \\
\text { al., 2005) }\end{array}$ \\
\hline Coastal taipan & Oxyuranus scutellatus & $42 \pm 3$ & $\begin{array}{l}\text { (Crachi et al., } \\
\text { 1999a) } \\
\text { (Crachi et al., }\end{array}$ \\
\hline Papuan taipan & Oxyuranus scutellatus canni & $44 \pm 5,48 \pm 5$ & $\begin{array}{l}\text { 1999a)(Crachi } \\
\text { et al., 1999b) }\end{array}$ \\
\hline Collett's snake & Pseudechis colletti & $56 \pm 5$ & $\begin{array}{l}\text { (Ramasamy et } \\
\text { al., 2005) }\end{array}$ \\
\hline Brown-headed snake & Glyphodon tristis & $100 \pm 8$ & $\begin{array}{l}\text { (Kuruppu et al., } \\
\text { 2005a) }\end{array}$ \\
\hline Mulga or King brown snake & Pseudechis australis & $>60$ & $\begin{array}{l}\text { (Ramasamy et } \\
\text { al., 2005) }\end{array}$ \\
\hline
\end{tabular}

* This study 
Figure legends

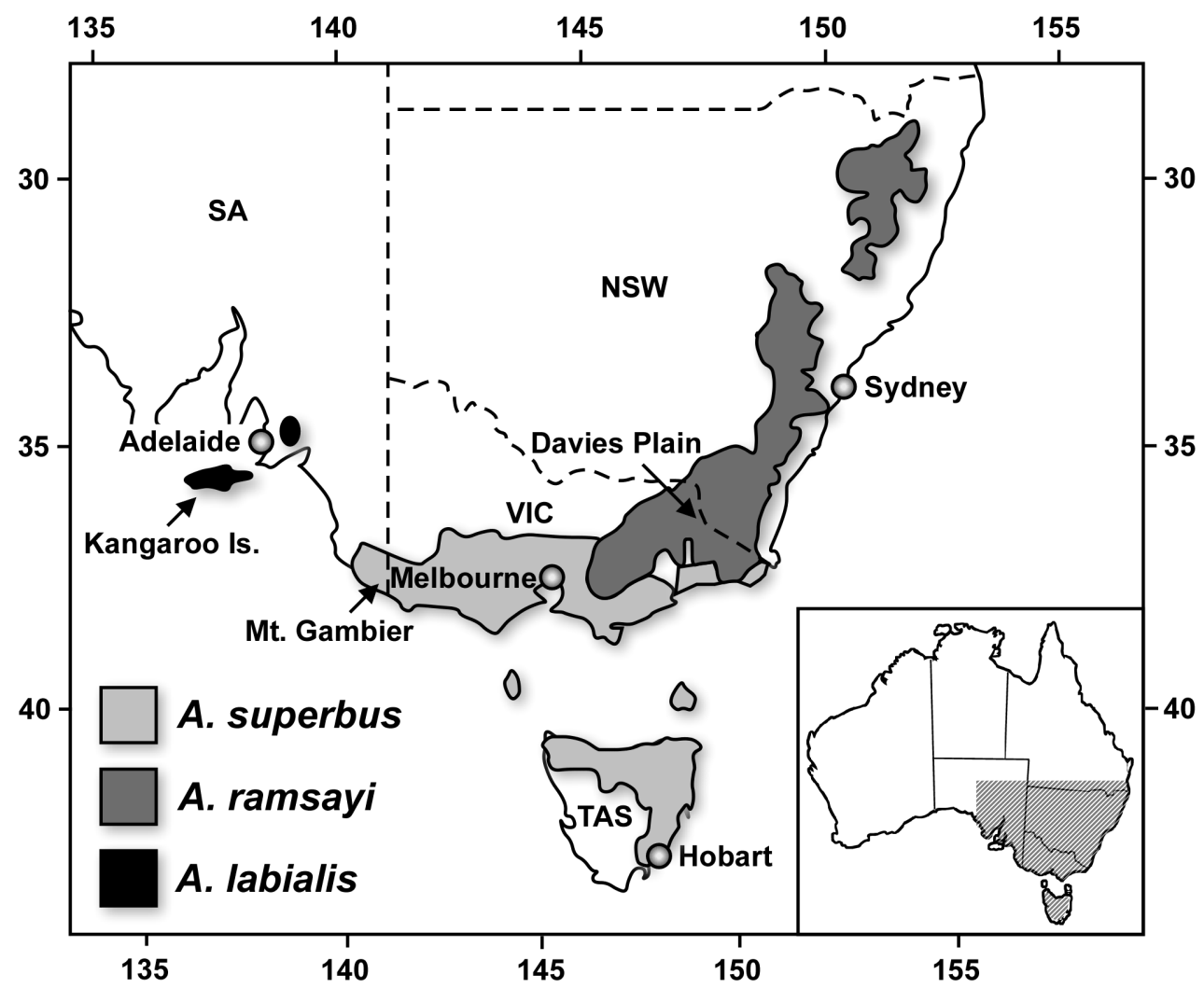

Fig. 1. Distribution of the three Australian copperhead species. Venom was sourced from specimens captured at Kangaroo Island, South Australia (A. labialis), Mount Gambier, South Australia (A. superbus) and Davies Plain, Victoria (A. ramsayi). Modified from Rawlinson, 1991 (Rawlinson, 1991). 


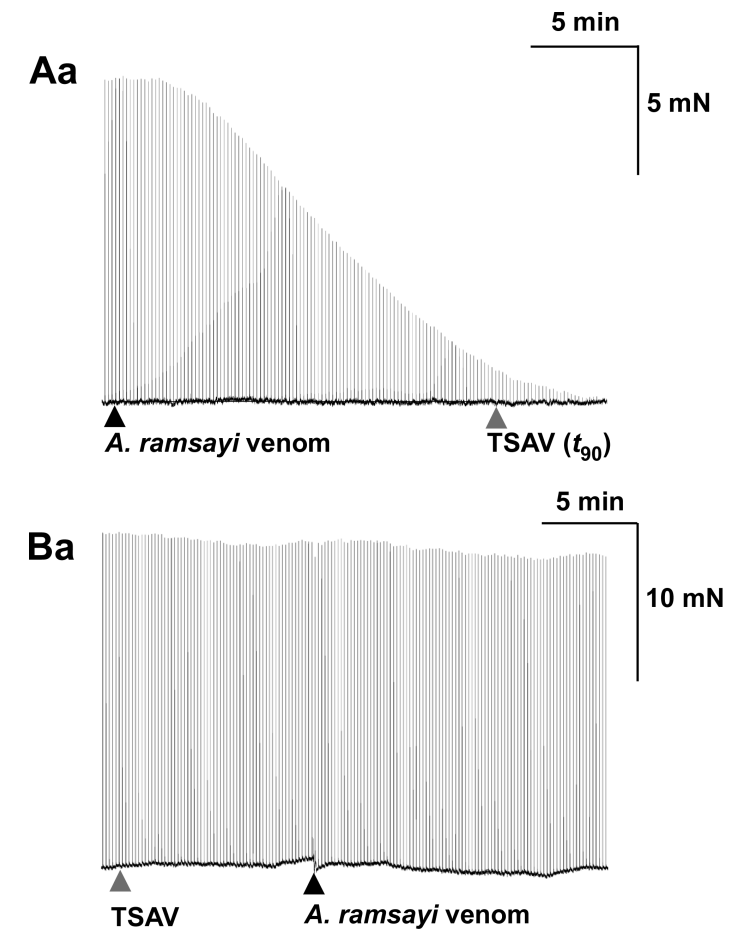

$A b$
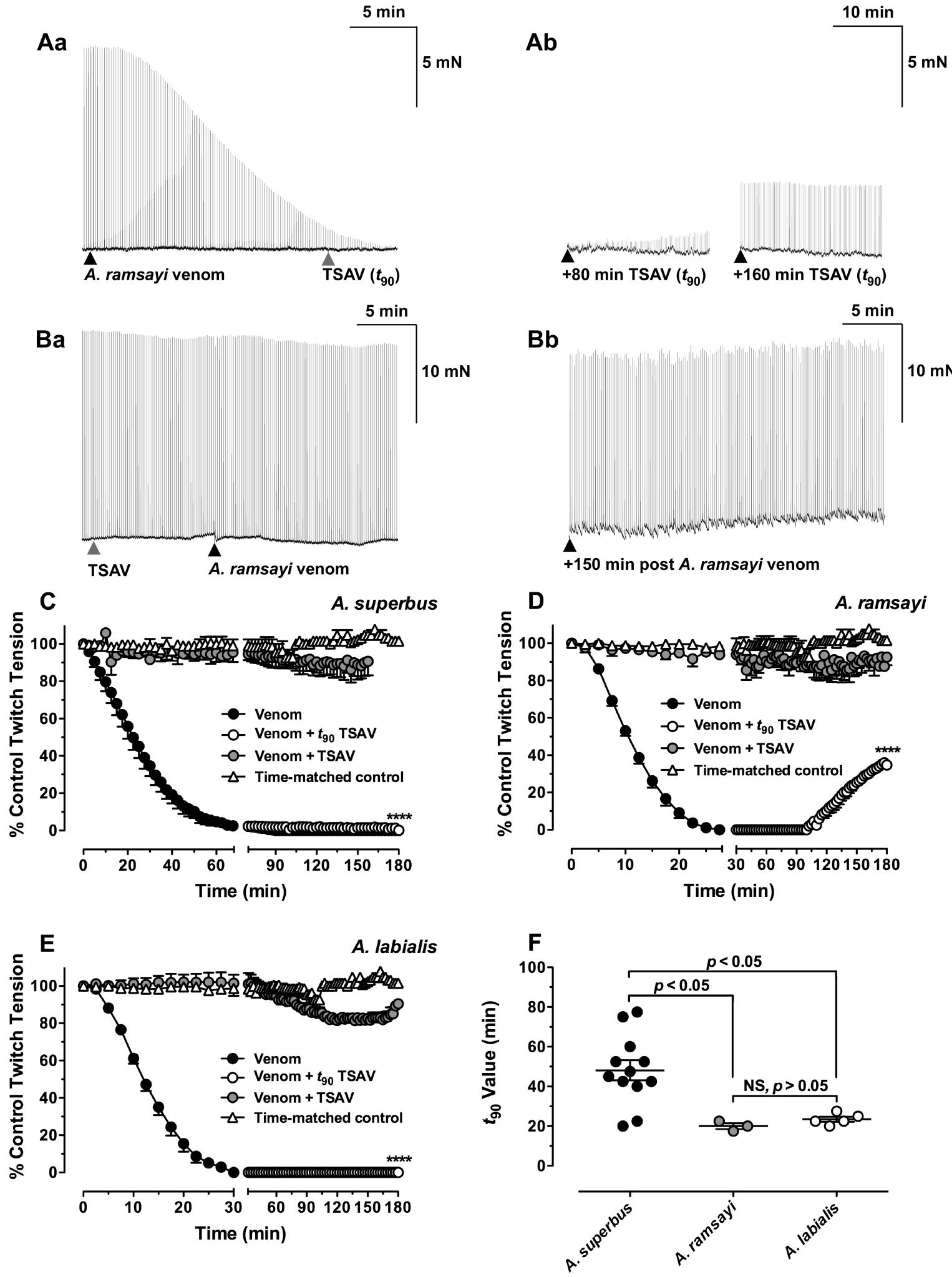

Fig. 2. Inhibition of indirectly-stimulated twitch contractions by whole Austrelaps venoms in the isolated CBCNM preparation. (A-B) Representative twitch tension traces showing the action of $A$. ramsayi venom on neuromuscular transmission and effects of $5 \mathrm{U} / \mathrm{ml}$ TSAV to prevent and partially reverse neurotoxicity. (Aa) Rapid inhibition of twitch tension following application of $10 \mu \mathrm{g} / \mathrm{ml} A$. ramsayi venom and $(\mathrm{Ab})$ partial reversal of twitch contractions 
$80 \mathrm{~min}$ (left panel) and $160 \mathrm{~min}$ (right panel) after application of TSAV applied at 90\% neuromuscular blockade [grey arrowhead labelled TSAV $\left(t_{90}\right)$ in panel Aa]. (B) Prevention of $A$. ramsayi venom neurotoxicity by a 10 min preincubation with TSAV (Ba), and 150 min after venom application (Bb). (C-E) Timecourse of inhibition of twitch contractions by whole venoms (closed circles) showing effects of $10 \mu \mathrm{g} / \mathrm{ml} A$. superbus $(C, n=6), A$. ramsayi (D, $n=3$ ) and $A$. labialis $(\mathrm{E}, n=5)$ in comparison to time-matched controls (open triangles, $n=$ 4). Partial recovery of twitches after the addition of TSAV at $90 \%$ neuromuscular blockade was only observed with $A$. ramsayi venom (open circles). Preincubation of TSAV 10 min prior to application of venom successfully prevented onset of neurotoxicity (grey circles, $n$ $=3$ ). Note the split $x$-axis. Data represent the mean \pm SEM. ${ }^{* * * *} p<0.0001$ vs. timematched control. (F) Scatter dot plot of $t_{90}$ values for each venom showing mean (wide horizontal line), SEM (narrow horizontal lines) and individual $t_{90}$ values (circles). NS, not significant. 

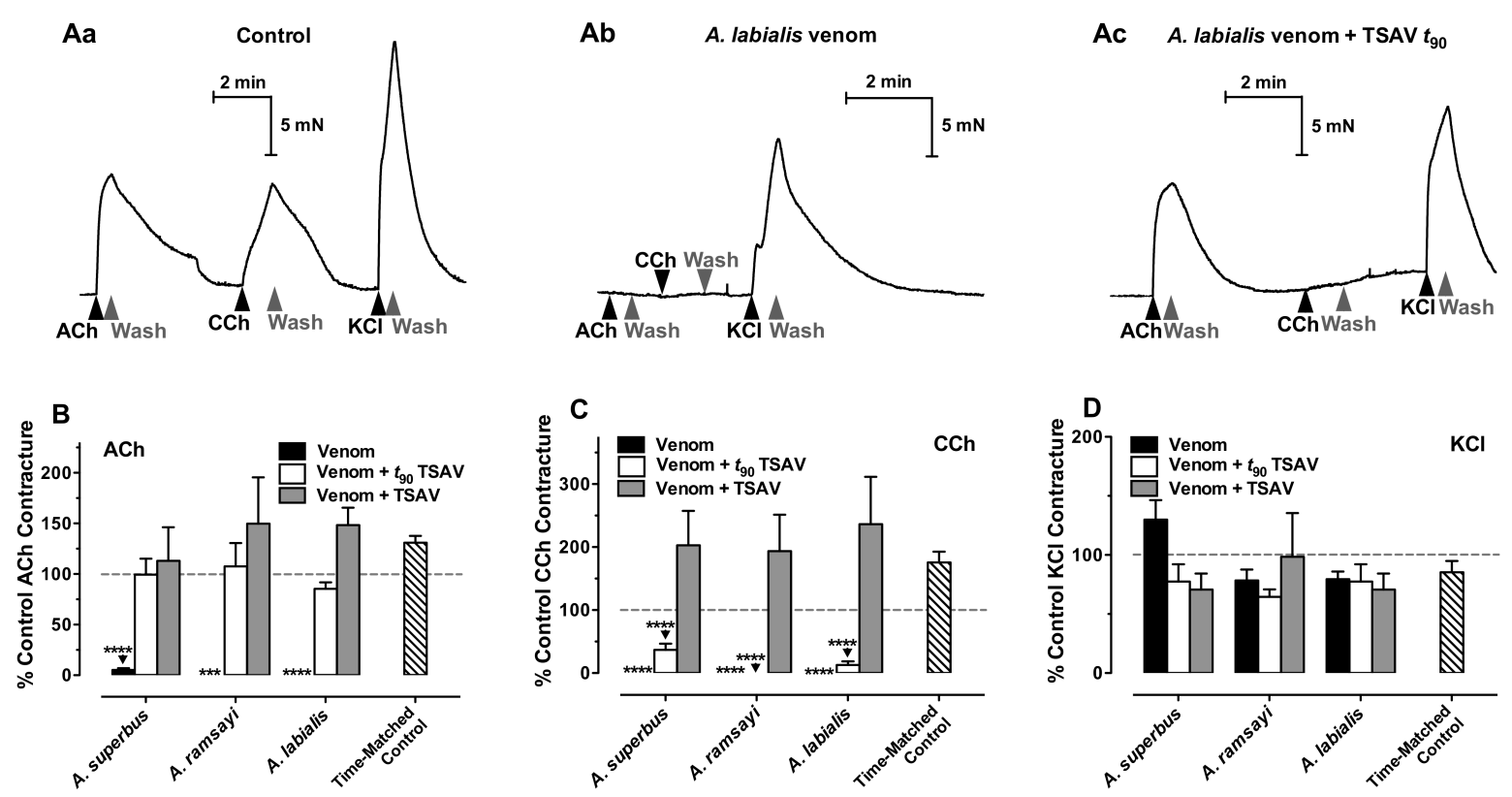

Fig. 3. Effect of Austrelaps venoms on slow fibre contractile responses to exogenous agonists in the isolated CBCNM preparation. (A) Typical effect of $10 \mu \mathrm{g} / \mathrm{ml}$ A. labialis venom on contracture responses to nicotinic agonists and $\mathrm{KCl}$ prior to $(\mathrm{Aa})$, and following (Ab), 30 min incubation with venom. Panel Ac shows the responses to exogenous agonists following a $180 \mathrm{~min}$ incubation of $5 \mathrm{U} / \mathrm{ml}$ TSAV added at $90 \%$ neuromuscular blockade $\left(t_{90}\right)$. Markers beneath each trace indicate the bath application of either $1 \mu \mathrm{M} \mathrm{ACh}, 20 \mu \mathrm{M}$ $\mathrm{CCh}$, or $40 \mathrm{mM} \mathrm{KCl}$ (black arrowheads) or washout with Krebs-Henseleit solution (grey arrowheads). (B-D) Data shows the percentage of control contracture responses to $\mathrm{ACh}$ (B), $\mathrm{CCh}(\mathrm{C})$ and $\mathrm{KCl}(\mathrm{D})$ after complete inhibition of twitch contractions by $10 \mu \mathrm{g} / \mathrm{ml}$ whole venom (closed bars) for $A$. superbus $(n=10), A$. ramsayi $(n=3)$ and A. labialis $(n=5)$. Agonist responses recorded in the presence of $5 \mathrm{U} / \mathrm{ml}$ TSAV applied at $t_{90}$ (open bars) were recorded at $180 \mathrm{~min}$ in the presence of $10 \mu \mathrm{g} / \mathrm{ml}$ venom from $A$. superbus $(n=4), A$. ramsayi $(n=3)$ and $A$. labialis $(n=4)$. Agonist responses recorded in the presence of 5 $\mathrm{U} / \mathrm{ml}$ TSAV preincubated $10 \mathrm{~min}$ prior to addition of $10 \mu \mathrm{g} / \mathrm{ml}$ of venom from $A$. superbus $(n$ $=3)$, A. ramsayi $(n=3)$ and $A$. labialis $(n=3)$ (grey bars) were recorded at $60 \mathrm{~min}$. Striped column represents time-matched control data recorded after 3-5 hours $(n=11)$. Note the increase in responses with $\mathrm{ACh}$ and $\mathrm{CCh}$, and decrease in responses to $\mathrm{KCl}$, from contractures recorded at time zero (dashed line). Data represent the mean \pm SEM. ${ }^{* * *} p<$ $0.001,{ }^{* * * *} p<0.0001$, significantly different from time-matched control response, two-way ANOVA. 

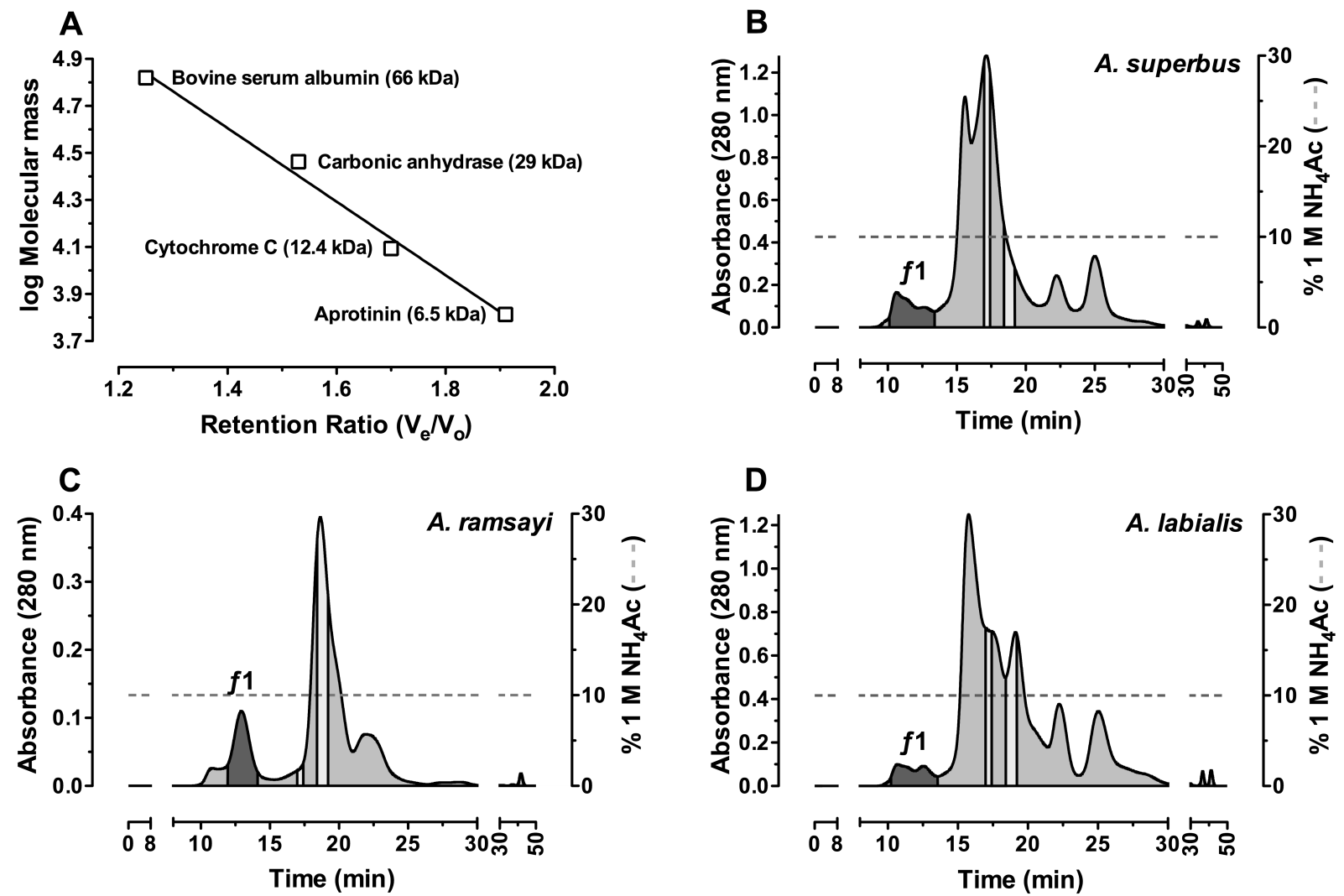

Fig. 4. Size-exclusion FPLC separation of Austrelaps venoms under non-reducing conditions. (A) Log molecular weight vs. retention ratio $\left(\mathrm{V}_{\mathrm{e}} / \mathrm{V}_{\mathrm{o}}\right)$ standard curve for the calibration of the Superdex G-75 column using a series of molecular weight standards. Calibrants were eluted with ammonium acetate $\left(0.1 \mathrm{M} \mathrm{NH}_{4} \mathrm{Ac}, \mathrm{pH} 6.8\right)$ at a flow rate of $0.75 \mathrm{ml} / \mathrm{min}$ (open squares). Representative size-exclusion FPLC chromatograms from $A$. superbus (B), A. ramsayi (C) and $A$. labialis (C) under non-reducing conditions with an isocratic flow of $0.1 \mathrm{M} \mathrm{NH}_{4} \mathrm{Ac} \mathrm{pH} 6.8$ (grey dotted line) at $0.75 \mathrm{ml} / \mathrm{min}$. Dark grey shaded fractions labelled ' $f 1$ ' representing high molecular mass components $\left(M_{r} 41\right.$ kDa to $>66$ $\mathrm{kDa}$ ) were collected for subsequent analysis. The two areas of the elution profile highlighted in light grey, from 17-19.2 min, indicate the mass range of $\mathrm{SPLA}_{2}$ proteins $(12,700-14,800 \mathrm{kDa}$; left hand bar) and postsynaptic a-neurotoxins $(6,700-8,850 \mathrm{kDa}$; right hand bar). Elution of proteins was monitored at $280 \mathrm{~nm}$. 

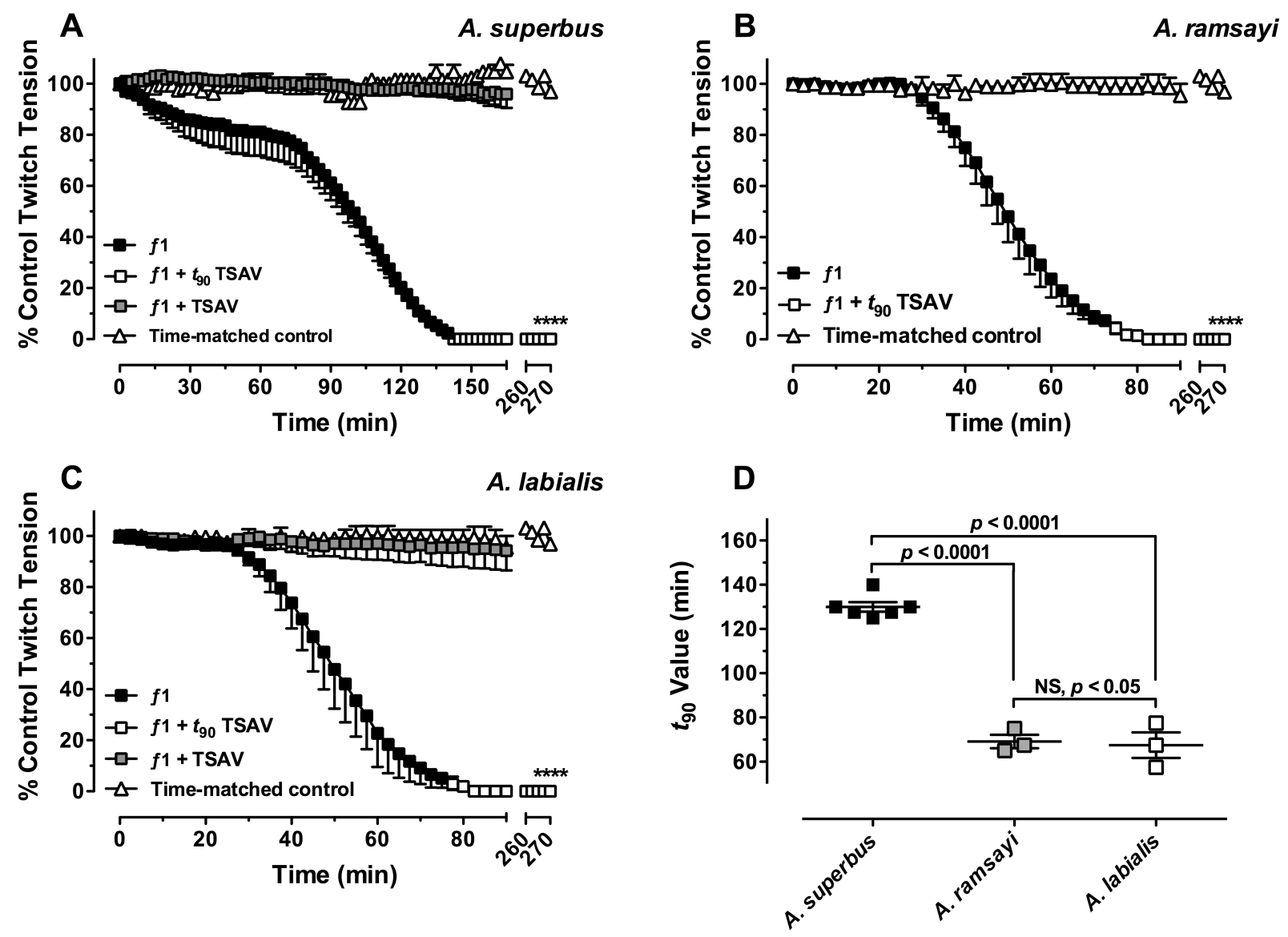

Fig. 5. Inhibition of indirectly-stimulated twitch contractions by the high molecular mass fraction ( $f 1)$ of Austrelaps venoms in the CBCNM preparation. Timecourse of inhibition of twitch contractions by $10 \mu \mathrm{g} / \mathrm{ml} f 1$ (closed circles) from (A) A. superbus ( $n=6)(B), A$. ramsayi $(n=3)$ and $(C)$ A. labialis $(n=3)$ in comparison to time-match controls $(n=4$; open triangles). No recovery of twitch contractions was observed after the addition of 5 $\mathrm{U} / \mathrm{ml}$ TSAV following complete neuromuscular blockade ( $n=3$; open circles). Note the split $x$-axis. A 10 min preincubation of $5 \mathrm{U} / \mathrm{ml}$ TSAV prior to application of $f 1$ from $A$. superbus and $A$. labialis was able to prevent the onset of neurotoxicity ( $n=3$; grey circles). The efficacy of TSAV in preventing the onset of neurotoxicity with $f 1$ from $A$. ramsayi was not determined. Data represent the mean \pm SEM. (D) Scatter dot plot of $t_{90}$ values for $f 1$ from each venom showing mean (wide horizontal line), SEM (narrow horizontal lines) and individual $t_{90}$ values (squares). 


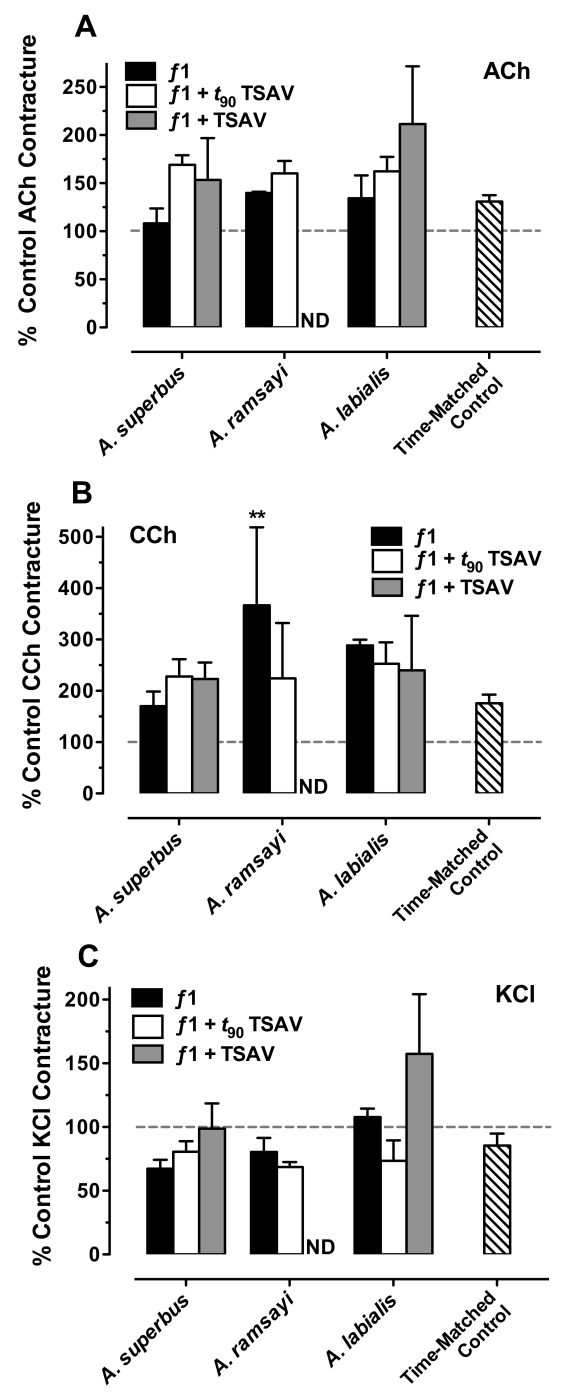

Fig. 6. Effect of the high molecular mass fraction ( $f 1)$ of Austrelaps venoms on slow fibre contractile responses to exogenous agonists in the isolated CBCNM preparation. (A-C) Data shows the percentage of control contracture responses to $\mathrm{ACh}(\mathrm{A}), \mathrm{CCh}(\mathrm{B})$ and $\mathrm{KCl}$ (C) after complete inhibition of twitch contractions by $10 \mu \mathrm{g} / \mathrm{ml} f 1$ (closed bars) from $A$. superbus $(n=6)$, A. ramsayi $(n=3)$ and A. labialis $(n=3)$. Agonist responses recorded in the presence of $5 \mathrm{U} / \mathrm{ml}$ antivenom applied at $t_{90}$ (open bars) following application of 10 $\mu \mathrm{g} / \mathrm{ml} f 1$ from $A$. superbus $(n=3)$, A. ramsayi $(n=3)$ and $A$. labialis $(n=3)$ were recorded at $180 \mathrm{~min}$. Agonist responses recorded in the presence of $5 \mathrm{U} / \mathrm{ml}$ antivenom preincubated $10 \mathrm{~min}$ prior to addition of $10 \mu \mathrm{g} / \mathrm{ml} f 1$ from $A$. superbus $(n=3)$ and $A$. labialis $(n=3)$ from were recorded at $60 \mathrm{~min}$ (grey bars). ND, not determined. Striped column represents timematched control data recorded after 3-5 hours $(n=11)$. Note the increase in responses with $\mathrm{ACh}$ and $\mathrm{CCh}$, and decrease in responses to $\mathrm{KCl}$, from contractures recorded at time zero (dashed line). Data represent the mean \pm SEM. ${ }^{*} p<0.01$, significantly different from time-matched control, two-way ANOVA. 


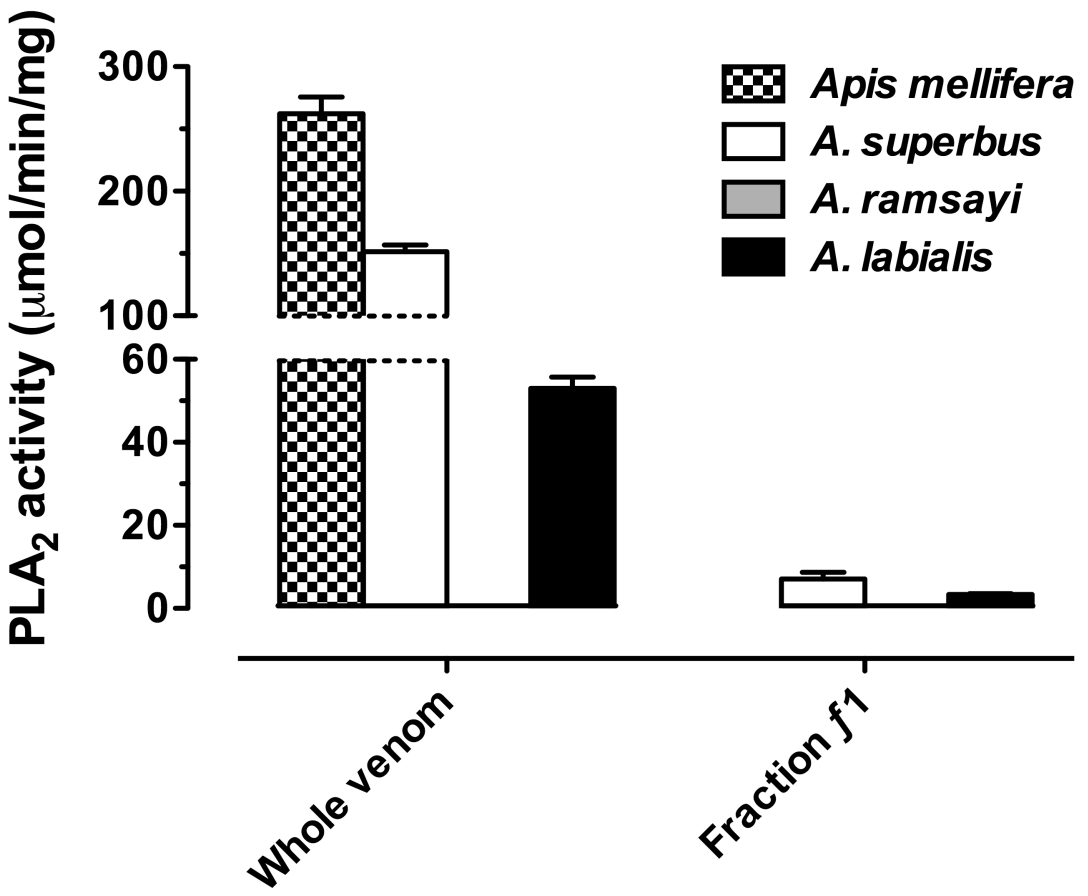

Fig. 7. $\mathrm{PLA}_{2}$ activity of whole Austrelaps venoms and their high molecular mass fraction $(f 1)$. Left hand columns show $\mathrm{PLA}_{2}$ activity of whole venom from $A$. superbus (open bar, $n$ $=3$ ), A. ramsayi (grey bar, $n=4$ ) and $A$. labialis (closed bar, $n=3$ ) as determined using the $\mathrm{SPLA}_{2}$ assay kit. Bee (Apis mellifera) venom (left-hand stippled bar, $n=11$ ) was used as a positive control. Right hand columns show $\mathrm{PLA}_{2}$ activity of the high molecular mass fraction $f 1$ from $A$. superbus (open bar, $n=4$ ), A. ramsayi (grey bar, $n=2$ ) and $A$. labialis (closed bar, $n=4$ ). Note that $\mathrm{PLA}_{2}$ activity was not detected in $A$. ramsayi venom or $f 1$ fraction. 

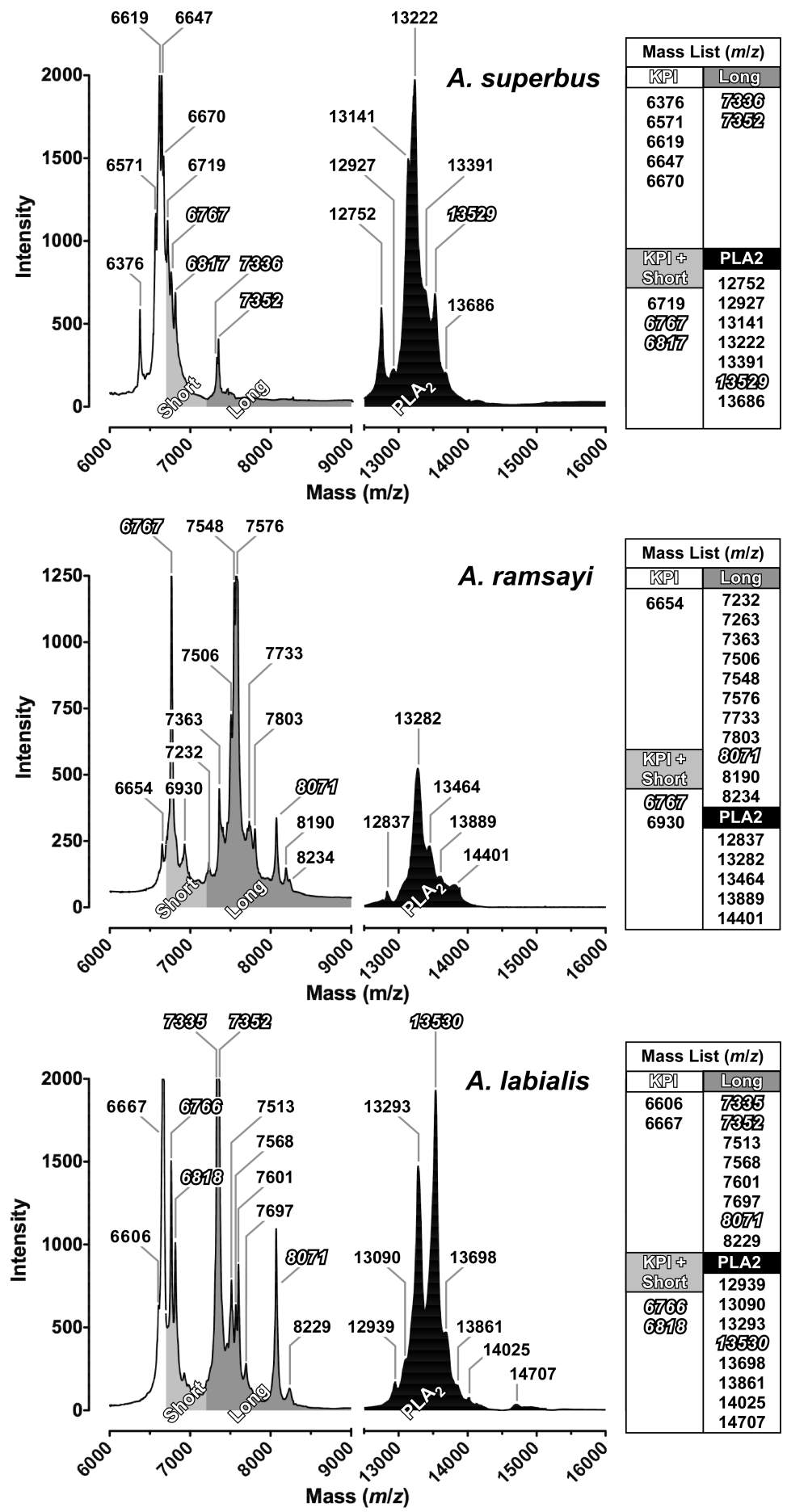

Fig. 8. MALDI-TOF mass spectra of Austrelaps venoms. Spectra are focused on masses $(\mathrm{m} / \mathrm{z})$ consistent with the presence of short-chain a-neurotoxins ('Short', light grey), longchain a-neurotoxins ('Long', dark grey) and monomeric sPLA $\mathrm{A}_{2}$ proteins ('PLA ${ }_{2}$ ', black). Major peaks are labelled, while a complete mass list is shown to the right of each panel. Masses common to at least two venoms are highlighted. Note the split $x$-axis. 